\title{
Characterization of Hypersensitive Resistance to Bacterial Spot Race T3 (Xanthomonas perforans) from Tomato Accession PI 128216
}

\author{
Matthew D. Robbins, Audrey Darrigues, Sung-Chur Sim, Mohammed Abu Taher Masud, and David M. Francis
}

\begin{abstract}
All authors: Department of Horticulture and Crop Science, The Ohio State University, Ohio Agricultural Research and Development Center, 1680 Madison Ave., Wooster, OH 44691; and fourth author: Horticulture Research Centre, Bangladesh Agricultural Research Institute, Joydebpur, Gazipur-1701, Bangladesh.

Current address of A. Darrigues: Clause Vegetable Seeds, Rue Louis Saillant, 26800 Portes-les-Valence, France.

Accepted for publication 29 April 2009.
\end{abstract}

\begin{abstract}
Robbins, M. D., Darrigues, A., Sim, S.-C., Masud, M. A. T., and Francis, D. M. 2009. Characterization of hypersensitive resistance to bacterial spot race T3 (Xanthomonas perforans) from tomato accession PI 128216. Phytopathology 99:1037-1044.

Bacterial spot of tomato is caused by four species of Xanthomonas. The accession PI 128216 (Solanum pimpinellifolium) displays a hypersensitive reaction (HR) to race T3 strains (predominately Xanthomonas perforans). We developed an inbred backcross (IBC) population $\left(\mathrm{BC}_{2} \mathrm{~S}_{5}, 178\right.$ families) derived from PI 128216 and $\mathrm{OH} 88119$ ( $S$. lycopersicum) as the susceptible recurrent parent for simultaneous introgression and genetic analysis of the HR response. These IBC families were evaluated in the greenhouse for HR to race T3 strain $X c v 761$. The IBC population was genotyped with molecular markers distributed throughout the genome in order to identify candidate loci conferring resistance. We treated the IBC population as a hypothesis forming generation to guide validation in subsequent crosses. Nonparametric

analysis identified an association between HR and markers clustered on chromosome $11(P<0.05$ to 0.0001$)$ and chromosome $6(0.04>P>$ $0.002)$. Further analysis of the IBC population suggested that markers on chromosome 6 and 11 failed to assort independently, a phenomenon known as gametic phase disequilibrium. Therefore, to validate markertrait linkages, resistant IBC plants were crossed with OH88119 and $\mathrm{BC}_{3} \mathrm{~F}_{2}$ progeny were evaluated for $\mathrm{HR}$ in the greenhouse. In these subsequent populations, the HR response was associated with the chromosome 11 markers $(P<0.0002)$ but not with the markers on chromosome 6 $(P>0.25)$. Independent $\mathrm{F}_{2}$ families were developed by crossing resistant IBC lines to $\mathrm{OH} 8245$, OH88119, and $\mathrm{OH} 7530$. These populations were genotyped, organized into classes based on chromosome 11 markers, and evaluated for resistance in the field. The PI 128216 locus on chromosome 11 provided resistance that was dependent on gene dosage and genetic background. These results define a single locus, $R x-4$, from PI 128216, which provides resistance to bacterial spot race T3, has additive gene action, and is located on chromosome 11.
\end{abstract}

Bacterial spot of tomato, Solanum lycopersicum L., is a disease complex with five races, T1 to T5 (8-10). It is caused by as many as four Xanthomonas spp.: Xanthomonas euvesicatoria (ex Doidge 1921) (5) sp. nov., sp. rev.; X. vesicatoria (Vauterin et al.1995) (30); X. perforans (10) sp. nov.; and X. gardneri (ex Šutic 1957) (26) sp. nov. as described by Jones et al. (10). Bacterial spot occurs throughout the world wherever tomato is grown and environmental conditions are favorable for disease development (25). In the tomato-growing region surrounding the Great Lakes of North America, three of the five bacterial spot races are present $(17,36)$ and $X$. gardneri has also been detected (9). The predominant race is T1 (X. euvesicatoria) followed by race T2 (X. vesicatoria), while race T3 (X. perforans) has been present for over 10 years. Race T4 has been identified in Florida and Central America but not in the Great Lakes region (9). The disease affects leaves, stems, and fruit and causes both yield and fruit grade losses through defoliation and fruit lesions (18). The development of tomato cultivars with resistance to bacterial diseases is a desirable goal but the process has been difficult due to the necessity of selecting for multiple diseases and the emergence of new species and races.

Corresponding author: D. M. Francis; E-mail address: francis.77@osu.edu

doi:10.1094/PHYTO-99-9-1037

(c) 2009 The American Phytopathological Society
Several sources of resistance to spot have been identified but, in most cases, the resistance is race specific. The $S$. lycopersicum breeding line Hawaii 7998 (Ha7998) has demonstrated both a reduction in symptoms in the field (field resistance) (20) and a hypersensitive reaction (HR) in the greenhouse (11) to spot race T1 (X. euvesicatoria). Three quantitative trait loci (QTL), $R x-1$, $R x-2$, and $R x-3$, were associated with the HR in a cross between Ha7998 and the $S$. pennellii accession LA716 $(31,37)$. The $R x-3$ locus was subsequently confirmed to provide HR as well as resistance in the field in a cross between Ha7998 and an elite breeding line, OH88119, and markers linked to $R x-3$ were identified (36). A second breeding line, Hawaii 7981 (Ha7981), provides HR to race T3 by the interaction between $a v r X v 3$ and a single gene, $X v 3$, which is yet to be mapped $(15,24)$. Field resistance to T3 from Ha7981 is quantitatively inherited and is based on $X v 3$ and modifier loci (21). Hypersensitivity (HR) to race T4 was identified from LA716 as Xv4 and mapped to chromosome 3 (1). The genetic characterization of this source of resistance requires clarification because the map position was not supported in subsequent studies (unpublished results). The $S$. lycopersicum var. cerasiforme accession, PI 114490, has shown resistance in the field to multiple races of spot $(19,23)$. Markertrait analysis was used to identify a QTL on chromosome 11 that had a large effect (13 to $57 \%$ of the variation) on resistance for races T1, T2, T3, and T4 (35). Another major QTL on chromosome 1 contributed 3 to $11 \%$ of resistance against races T2, T3, and T4. Additional minor QTL were identified that collectively contributed to resistance to all four races. 
An additional source of resistance to spot race T3 is the $S$. pimpinellifolium accession PI 128216. In a survey of several tomato accessions, PI 128216 and selections from the PI expressed HR when challenged by spot race T3 (22). Although some of the tomato accessions most resistant in the field also showed HR, the correlation between HR and field resistance was not complete (22). The clear HR response from PI 128216 to only race T3 has been used as a diagnostic to classify Xanthomonas strains into races (17). However, the genetic basis of resistance from PI 128216 to race T3 has not been described.

Given the complexity of the bacterial spot disease complex and the existence of multiple sources of resistance, it would be desirable to better characterize each source in order to facilitate pyramiding of genes effective against multiple races and against other bacterial diseases. The mapping of $R x-3$, for example, provided an opportunity to combine this locus with Pto, which confers resistance to race 0 of bacterial speck (Pseudomonas syringae pv. tomato), using marker-assisted selection to identify coupling phase recombinants (34). Therefore, our goal was to describe the genetic basis of the HR reaction to spot race T3 in PI 128216, determine if HR provides resistance in the field, and pyramid this resistance with other bacterial resistance genes. We identified a locus on chromosome $11, R x-4$, that provides HR in greenhouse inoculations and resistance in the field. We combined this locus with Pto and $R x$-3 in order to develop breeding lines with resistance to multiple bacterial diseases.

\section{MATERIALS AND METHODS}

Plant material. We created an inbred backcross (IBC) population for simultaneous introduction and characterization of spot resistance (32). The IBC population was developed from a cross between OH88119 (S. lycopersicum) and PI 128216. OH88119 is an elite processing tomato parent chosen because of its early and concentrated fruit set as well as susceptibility to bacterial disease (2). PI 128216 is an accession of the United States Department of Agriculture (USDA) National Plant Germplasm System (NPGS) collection. Passport data in the Germplasm information network (GRIN) describes PI 128216 as an accession of $S$. lycopersicum collected in Bolivia in 1938. However, the accession morphologically appears to be $S$. pimpinellifolium, with characteristic foliage, flowers, current-sized fruit, and an indeterminate growth habit (22).

The two parents were crossed and the hybrid was backcrossed for two generations to $\mathrm{OH} 88119$ as the recurrent parent to create the $\mathrm{BC}_{2}$ population, which consisted of 94 individuals. Two random progeny from each $\mathrm{BC}_{2}$ individual were self-pollinated and the seed was saved separately to generate $188 \mathrm{BC}_{2} \mathrm{~S}_{1}$ lines. Individual families were then advanced by self-pollination and single-seed descent for four more generations. The $\mathrm{BC}_{2} \mathrm{~S}_{5}$ population consisted of 178 lines because some were lost in the process of generating the succeeding filial generations (4). The theoretical expectation is that a low proportion (12.5\%) of the donor S. pimpinellifolium parent is represented in each line and that each line is homozygous at $93.75 \%$ of its loci (32).

Additional segregating populations were screened for HR in the greenhouse to confirm marker-trait associations identified in the IBC population. Three individuals from the IBC population, 06.8040, 06.8068, and 06.8145, were chosen based on the presence of HR when inoculated with T3 strains and because they contained candidate loci associated with HR in the IBC population (Table 1). These three lines were individually crossed back to OH88119 to develop three independent populations.

Progeny from four crosses were evaluated in the field for resistance to spot race T3. The four crosses used IBC lines as female parents and were $06.8145 \times \mathrm{OH} 8245,06.8145 \times \mathrm{OH} 7530$, $06.8145 \times \mathrm{OH} 88119$, and $06.8068 \times \mathrm{OH} 88119$. Cv. OH8245 was chosen based on its status as an elite parent for processing tomato hybrids $(2,3)$ and observations that it possesses a nonblighting tolerance to spot when symptoms are present. Crosses were made to $\mathrm{OH} 7530$ in order to pyramid HR to race T3 with the resistance genes $R x-3$, which provides an HR response to spot race T1, and $P$ to, which provides an HR response to bacterial speck race 0 (34). Hybrids from these crosses were self-pollinated to create $F_{2}$ populations for marker-assisted selection and disease evaluation.

Experimental design. Greenhouse evaluations of HR in segregating populations were based on comparisons to Ha7981 and PI 128216 as resistant controls and OH88119 as the susceptible control. The growth and care of greenhouse plants followed established methods (36). For the initial screening of the IBC population, 178 lines were evaluated in a randomized complete block (RCB) design with two replications. For confirmation of marker-trait associations, 48 individuals from the $06.8040 \times$ OH88119 $\mathrm{F}_{2}$ population, 48 individuals from the $06.8068 \times$ $\mathrm{OH} 88119 \mathrm{~F}_{2}$ population, and 205 individuals from the $06.8145 \times$ OH88119 $\mathrm{F}_{2}$ population were evaluated in a completely randomized design with a single replication.

Disease evaluation was conducted in the field to test the hypothesis that the locus associated with the HR response in the greenhouse also provides resistance in the field. Plants were first sown in the greenhouse in 288-cell flats with plant care and growth conditions as previously described (36). Individual plants were genotyped with two markers, SL10615i and SL10737i, which were associated with the HR response in the IBC population and confirming generations. Plants were then organized into genotypic classes (homozygous for the PI 128216 allele conditioning HR, heterozygous, and homozygous for the susceptible allele). Seedlings were spray inoculated (described below) and transplanted into the field in Wooster, $\mathrm{OH} 1$ week following inoculation. To test the effect of genetic background, four segregating populations were tested, two in the OH88119 background and one each in the OH8245 and OH7530 background (as described above). The trial was established as a replicated RCB design with two replications consisting of 10 plants per plot.

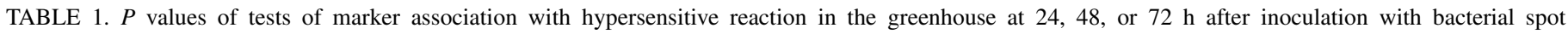
(Xanthomonas perforans) race T3 in four segregating tomato populations ${ }^{\mathrm{a}}$

\begin{tabular}{|c|c|c|c|c|c|c|c|}
\hline \multirow[b]{2}{*}{ Marker } & \multirow[b]{2}{*}{ Chromosome $^{\mathrm{b}}$} & \multicolumn{3}{|c|}{ IBC population } & \multirow{2}{*}{$\frac{06.8040}{72 \mathrm{~h}}$} & \multirow{2}{*}{$\frac{06.8068}{72 \mathrm{~h}}$} & \multirow{2}{*}{$\frac{06.8145}{72 \mathrm{~h}}$} \\
\hline & & $24 \mathrm{~h}$ & $48 \mathrm{~h}$ & $72 \mathrm{~h}$ & & & \\
\hline LEOH200 & 6 & 0.0021 & 0.0039 & 0.0031 & 0.8234 & NA & 0.2507 \\
\hline LEOH112 & 6 & 0.0378 & 0.0067 & 0.0072 & 0.6772 & NA & 0.2932 \\
\hline SL10737i & 11 & 0.0434 & $<0.0001$ & $<0.0001$ & NA & 0.0002 & $<0.0001$ \\
\hline SL10615i & 11 & $<0.0001$ & $<0.0001$ & $<0.0001$ & NA & $<0.0001$ & $<0.0001$ \\
\hline CosOH57 & 11 & $<0.0001$ & $<0.0001$ & $<0.0001$ & NA & $<0.0001$ & $<0.0001$ \\
\hline SL20181 & 11 & $<0.0001$ & $<0.0001$ & $<0.0001$ & $<0.0001$ & $<0.0001$ & $<0.0001$ \\
\hline
\end{tabular}

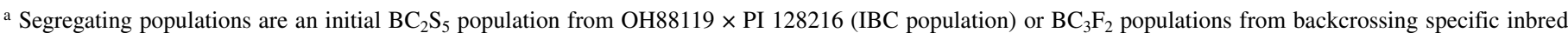
backcross (IBC) lines 06.8040, 06.8068, and 06.8145 with OH88119. NA indicates that the marker was not segregating in the cross and could not be tested.

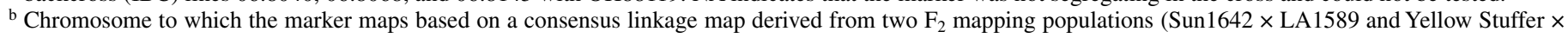
LA1589) (unpublished data). 
Inoculum preparation and inoculation. The $X$. perforans race T3 strain used in the study was Xcv761 (16). Inoculum was produced by growing the bacteria on yeast, dextrose, and calcium carbonate (YDC) agar medium (14) at $28^{\circ} \mathrm{C}$ for 48 to $72 \mathrm{~h}$. Bacterial cells were washed from the agar plates with sterile, double-distilled water and the suspensions were standardized to an absorbance at $600 \mathrm{~nm}$ of 0.15 , a concentration of $\approx 3 \times 10^{8}$ $\mathrm{CFU} / \mathrm{ml}$. For evaluations of HR response in the greenhouse, inoculations were performed by leaf infiltration on two leaflets per plant. The bacterial suspension was injected on the underside of each young, fully expanded leaflet using a 3-ml syringe without a needle until the area of infiltration reached $1.5 \mathrm{~cm}$ in diameter. Control plants were also mock inoculated with sterile $\mathrm{H}_{2} \mathrm{O}$ to provide a comparison. Plants were kept at 20 to $25^{\circ} \mathrm{C}$ in the greenhouse with supplemental lighting. For the field trial, plants were inoculated in the greenhouse 1 week prior to transplanting by covering the plants with a fine mist using a Preval Spray Gun (Preval Sprayer Division, Yonkers, NY) as previously described (34).

Disease scoring. Plants were scored for the HR response in the greenhouse using a qualitative scale whereas field symptoms were scored using a quantitative scale. In the greenhouse, plants were visually inspected for the HR response at 24, 48, and $72 \mathrm{~h}$ after inoculation. Each of the two inoculated leaves per plant was scored as HR or a susceptible response. The scores from both leaves were combined into a single score for each plant for data analysis. If one of the leaves showed no response and the other showed a clear response, the plant was scored according to the clear response. Single plants with ambiguous responses were excluded from the statistical analyses. In the field, plants were rated for disease severity on a per plot basis using the scale of Horsfall and Barratt (6), where $1=0,2=0$ to $3,3=3$ to $6,4=6$ to $12,5=12$ to $25,6=25$ to $50,7=50$ to $75,8=75$ to $87,9=87$ to $94,10=94$ to $97,11=97$ to 100 , and $12=100 \%$ diseased tissue. Plots were rated twice, with the early rating timed to correspond to when $80 \%$ of plots had reached the mature green stage of fruit ripeness. The late rating was timed to correspond to when $80 \%$ of the fruit were ripe, the approximate time of harvest for maximum marketable yield and grade quality.

Molecular marker analysis and mapping. Procedures for DNA extraction, polymerase chain reaction (PCR), and electrophoresis used in the analysis of these populations were described previously $(12,33,36)$. In total, 352 primer pairs, consisting of simple sequence repeat (SSR), insertion/deletion (indel), and single nucleotide polymorphism (SNP) markers, were screened for polymorphisms between the two parental lines of the $\mathrm{BC}_{2} \mathrm{~S}_{5}$ population. We identified 70 markers polymorphic between OH88119 and PI 128216 and selected 53 markers scattered throughout the genome to genotype the IBC population for marker-trait analysis. Only those markers significantly associated with HR were used in subsequent populations, except for the marker Rx3-L1. This marker was used to genotype the OH7530derived $\mathrm{F}_{2}$ population for the $R x-3$ introgression from Hawaii 7998.

In order to determine the genomic location of the locus conditioning the HR response, 205 individuals from the $06.8145 \times$ $\mathrm{OH} 88119 \mathrm{~F}_{2}$ population were genotyped with additional markers on chromosome 11 (Fig. 1). For mapping purposes, the phenotypic data for the HR response was treated as a dominant marker. A linkage map was created from these data using JoinMap 3.0 (29). Based on the marker order from a consensus linkage map of the entire chromosome 11 derived from two $F_{2}$ mapping populations (Sun1642 × LA1589 and Yellow Stuffer $\times$ LA1589) (unpublished data), the fixed marker order of SL10737i, SL10615i, SL20181, and SL10027 was utilized. The map was assembled with the thresholds for parameters within JoinMap of 1.00 for $\log$ of the likelihood ratio, 0.4 for REC, 5.0 for jump, and 1 for ripple while employing the Kosambi mapping function.
All markers used in this study were reported elsewhere $(28,36)$. Primers sequences $\left(5^{\prime}\right.$ to $\left.3^{\prime}\right)$ include $\mathrm{CosOH} 57$ (F: tgccaaaagcacagtacaa, R: cgcctcctatcttccaaactt), SL10027 (F: gatccagtttccctcttaccg, R: ccattagagccaagacgctc), SL10615i (F: tttccacaggtcattcttcc, R: tgggggatgagagttgtaatg), SL10737i (F: ccactcctgggactcaaatc, R: tggacccacaggtaatgagg), SL10915 (F: ggcaaaggaagaaatcccat, R: gagttccaccatgagacaagc), SL20181 (F: tcgactatgccatttgcttg, R: ttcaggtgcagtagaaagctca), SSR637 (F: aatgtaacaacgtgtcatgattc, R: aagtcacaaactaagttaggg), TOM144 (F: ctgtttacttcaagaaggctg, R: actttaactttattattgcgacg), and TOM196 (F: cctccaaatcccaaaactct, R: tgtttcatccactatcacga). Markers SSR637, TOM196, and TOM144 are SSR markers that were detected as amplicon size polymorphisms on polyacrylamide gels using the LI-COR-IR2 4200 system (LI-COR Biosciences, Lincoln, NE). Markers SL10615i and SL10737i are based on indels and were also scored using the LI-COR system. Markers SL10027, SL10915, and SL20181 are based on SNPs and were detected using allele-specific primer extension (ASPE) assays (13) on the Luminex 200 system (Luminex Corporation, Austin, TX). CosOH57 was based on a SNP that was detected using the restriction enzyme Tth111I (New

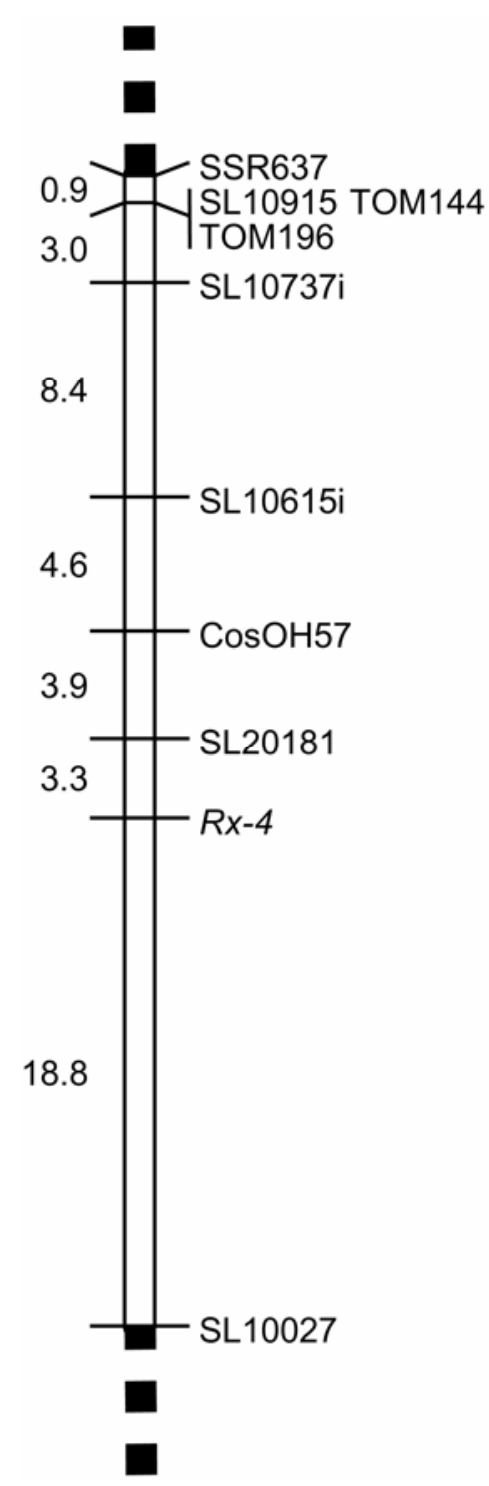

Fig. 1. Genetic linkage map location of $R x-4$, which provides resistance to bacterial spot race T3 (Xanthomonas perforans), relative to molecular markers on chromosome 11 of tomato. Map distances (centimorgans) between each marker cluster are on the left with marker names on the right. The dashed lines at the top and the bottom of the linkage group indicate that this map only covers a portion of chromosome 11 . 
England BioLabs Incorporated, Ipswich, MA) in a cleaved amplified polymorphic sequence (CAPs) approach. Polymorphisms and sequence context for markers with the "SL" prefix are included in the supplementary material of Van Deynze et al. (28).

Statistical analysis. The extent of linkage and gametic phase disequilibrium was tested in the IBC population by calculating $R^{2}$ values and a $\chi^{2}$ goodness-of-fit test for independent assortment for all possible pairwise marker combinations. Pairwise $R^{2}$ values were calculated using GGT 2.0 software (27). Calculations for the $\chi^{2}$ test were based on an expected frequency of 0.125 for individuals homozygous for the PI 128216 allele at any marker locus in the IBC population because only $12.5 \%$ of the genome is expected to be from the donor parent in the $\mathrm{BC}_{2} \mathrm{~S}_{5}$ generation. To visualize genomic locations in disequilibrium, the $P$ value for each pairwise test was coded by significance level and plotted in a heat map (Fig. 2).

In each segregating population, deviation from expected segregation ratios were tested using a $\chi^{2}$ goodness-of-fit test. In the $F_{2}$ populations screened for $H R$ in the greenhouse, segregation of HR was tested against several ratios supporting both one-locus and two-loci hypotheses. These ratios were 3:1 (single locus, dominant gene), 9:7 (two loci, duplicate recessive), 15:1 (two loci, duplicate dominant), and 13:3 (two loci, dominant-recessive epistatic interaction) ratios.

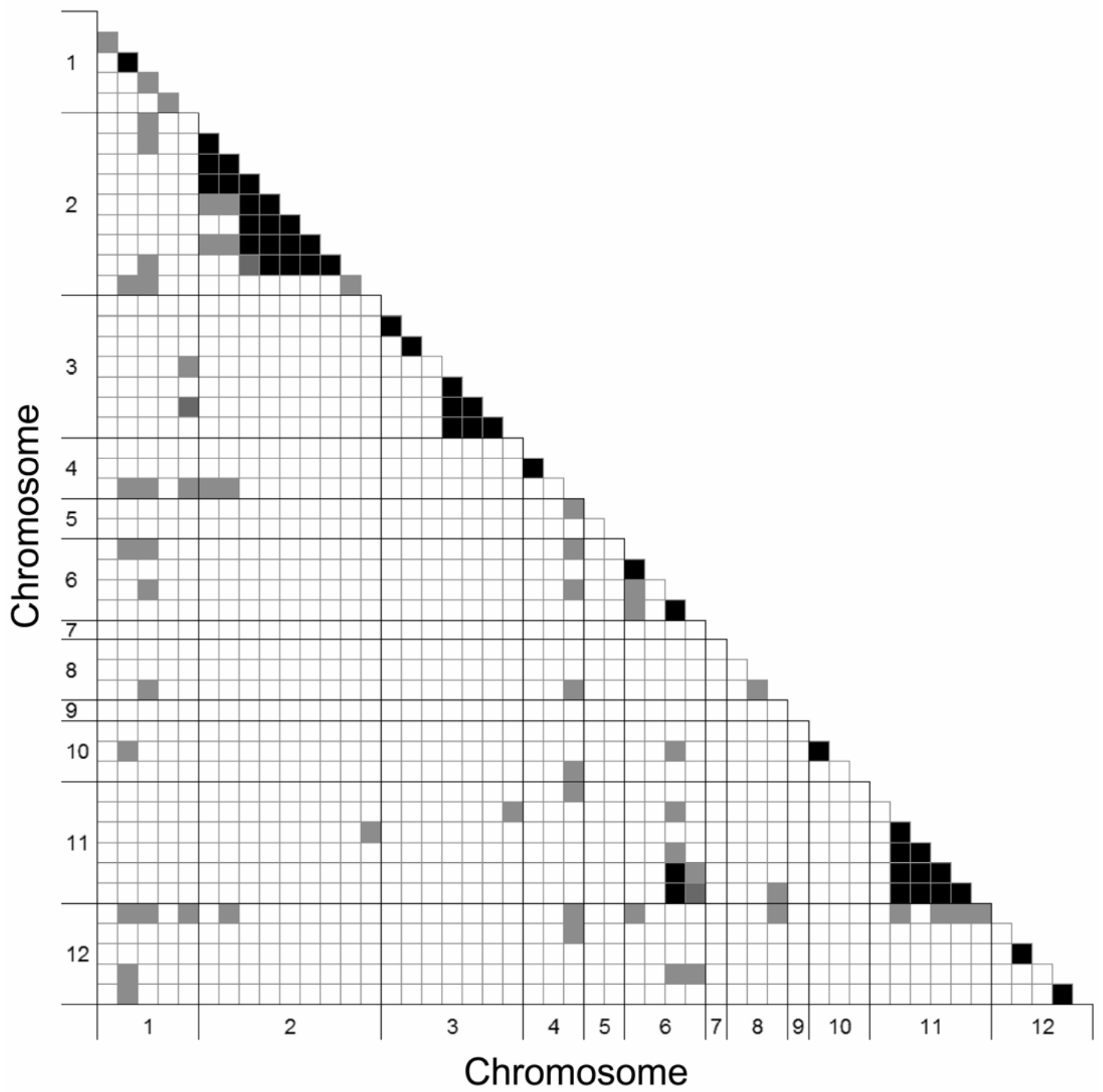

Fig. 2. Heat map based on pairwise $\chi^{2}$ goodness-of-fit tests for independent assortment of markers in the PI 128216 inbred backcross population $\left(\mathrm{BC}_{2} \mathrm{~S}_{5}\right)$. Each column or row represents one marker and markers are ordered by genomic location on the reference map. Each cell indicates the $P$ value of the $\chi^{2}$ test between two markers as $P>0.05$ (white), $0.05 \geq P>0.01$ (light gray), $0.01 \geq P>0.001$ (dark gray), or $P \leq 0.001$ (black). Several markers on chromosomes 6 and 11 failed to assort independently in the inbred backcross population. 
Marker-trait associations were tested for significance using the nonparametric Kruskal-Wallace test as implemented in the SAS (version 9.1; SAS Software, Cary, NC) procedure NPAR1WAY with the Wilcoxon option specified. For the IBC population, each marker was tested against the 24-, 48-, and 72-h ratings for HR. To adjust for multiple comparisons, a marker had to have a $P$ value $<0.01$ in at least two time points to be declared significantly associated with the HR response. For the confirming generations in the greenhouse, the same analysis was performed except that each marker was tested against the 72-h ratings only.

Marker-trait associations were tested in the field evaluation using analysis of variance (ANOVA) implemented through the general linear model (GLM) procedure in SAS (version 9.1; SAS Software). Replications were considered random effects while genotypes were considered fixed effects, with the $F$ test specified as Marker/Genotype(Marker). Mean separations were conducted based on the least significant difference $\left(\mathrm{LSD}_{0.05}\right)$ only after the $F$ test for genotypes was significant at $P<0.05$. Specific comparisons were made within the ANOVA for the dosage effect of alleles at the HR locus, the effect of genetic background, and the effect of $R x-3$ in the OH7530 genetic background.

\section{RESULTS}

Evaluation of the IBC population in the greenhouse demonstrated clear differences between lines that produced HR and lines that produced a water-soaked lesion characteristic of suscepti- bility. Of the 178 lines tested, 170 gave consistent results between replicate plants and replicate inoculations. Associations of HR with marker data were tested using a nonparametric analysis. Of the 53 markers tested initially, four (LEOH200, LEOH112, SL10737i, and SL10615i) were significantly associated with HR where $P<0.01$ in more than one time point (Table 1). These four markers represent two genomic locations, one on chromosome 6 and one on chromosome 11.

Visual observation of the marker data indicated that a higher than expected number of resistant IBC lines contained both chromosome 6 and chromosome 11 introgressions from PI 128216. The $R^{2}$ values of marker pairs between these two regions were 7 to $11 \%$ higher than the rest of the genome. The results of a $\chi^{2}$ test for independent assortment of all possible marker pairs in the IBC population are presented in Figure 2. The nonindependent assortment of linked loci (i.e., linkage disequilibrium) is represented by the shaded areas along the diagonal of the figure. There were several pairs of markers from separate chromosomes that significantly deviated from the expectation of independent assortment (i.e., gametic phase disequilibrium). The most concentrated and most highly significant areas of gametic phase disequilibrium were between markers on chromosomes 6 and 11. Because these markers were also associated with HR, independent segregating populations were required to determine whether the association of both genomic locations with resistance was due to separate genetic factors or gametic phase disequilibrium in the IBC population.

TABLE 2. Disease ratings of tomato genotypes inoculated with bacterial spot (Xanthomonas perforans) race T3 in the field in $2008^{\mathrm{a}}$

\begin{tabular}{|c|c|c|c|c|c|c|c|}
\hline \multicolumn{4}{|c|}{ Early rating } & \multicolumn{4}{|c|}{ Late rating } \\
\hline Test, genotype ${ }^{b}$ & Background $^{\mathrm{c}}$ & Mean $^{\mathrm{d}}$ & $\mathrm{T}$ grouping $\mathrm{e}$ & Genotype & Background & Mean & $\mathrm{T}$ grouping \\
\hline \multicolumn{8}{|l|}{$R x-4$} \\
\hline $\mathrm{rr}$ & $\ldots$ & 4.1 & A & $\mathrm{rr}$ & $\ldots$ & 7.9 & A \\
\hline $\mathrm{Rr}$ & $\ldots$ & 2.5 & B & $\mathrm{Rr}$ & $\ldots$ & 4.3 & B \\
\hline RR & $\ldots$ & 1.9 & $\mathrm{C}$ & RR & $\ldots$ & 3.6 & B \\
\hline$P$ value & $\ldots$ & 0.0032 & $\ldots$ & $\ldots$ & $\ldots$ & 0.0001 & $\ldots$ \\
\hline $\operatorname{LSD}_{(0.05)}$ & $\ldots$ & 0.5 & $\ldots$ & $\ldots$ & $\ldots$ & 1.3 & $\ldots$ \\
\hline \multicolumn{8}{|l|}{ Background } \\
\hline$\ldots$ & OH88119 & 3.2 & A & $\ldots$ & OH88119 & 5.8 & A \\
\hline$\ldots$ & $\mathrm{OH} 7530$ & 2.5 & $\mathrm{AB}$ & $\ldots$ & OH7530 & 4.7 & A \\
\hline$\ldots$ & OH8245 & 2.3 & B & $\ldots$ & $\mathrm{OH} 8245$ & 4.7 & A \\
\hline$P$ value & $\ldots$ & 0.0463 & $\ldots$ & $\ldots$ & $\ldots$ & 0.1083 & $\ldots$ \\
\hline $\operatorname{LSD}_{(0.05)}$ & $\ldots$ & 0.7 & $\ldots$ & $\ldots$ & $\ldots$ & 1.2 & $\ldots$ \\
\hline \multicolumn{8}{|l|}{ Genotype } \\
\hline OH88119 (xxrr) & $\ldots$ & 5.5 & A & Xxrr & OH88119 (06.8145) & 9.0 & A \\
\hline Xxrr & OH88119 (06.8145) & 5.5 & A & OH88119 (xxrr) & & 8.0 & A \\
\hline xxrr & OH88119 (06.8068) & 4.0 & $\mathrm{~B}$ & Xxrr & OH88119 (06.8068) & 8.0 & A \\
\hline X_rr & OH7530 & 4.0 & B & Xxrr & OH7530 & 7.5 & A \\
\hline Ō̄7530 (XXrr) & $\ldots$ & 3.5 & $\mathrm{BC}$ & Xxrr & OH8245 & 7.0 & $\mathrm{AB}$ \\
\hline xxrr & OH8245 & 3.0 & $\mathrm{BCD}$ & $\mathrm{xxRr}$ & OH88119 (06.8145) & 5.0 & $\mathrm{BC}$ \\
\hline $\mathrm{xxRr}$ & OH88119 (06.8068) & 3.0 & $\mathrm{BCD}$ & $\mathrm{xxRr}$ & OH88119 (06.8068) & 5.0 & $\mathrm{BC}$ \\
\hline $\mathrm{xxRr}$ & OH88119 (06.8145) & 2.5 & $\mathrm{CDE}$ & OH8245 (xxrr) & $\ldots$ & 5.0 & $\mathrm{BC}$ \\
\hline $\mathrm{xxRR}$ & OH88119 (06.8068) & 2.5 & $\mathrm{CDE}$ & xxRR & OH88119 (06.8068) & 4.5 & $\mathrm{CD}$ \\
\hline OH8245 (xxrr) & $\ldots$ & 2.5 & CDE & OH7530 (XXrr) & $\ldots$ & 4.5 & $\mathrm{CD}$ \\
\hline $\mathrm{xxRr}$ & OH8245 & 2.0 & DE & xxRR & OH8245 & 4.0 & $\mathrm{CD}$ \\
\hline Ha7981 (xxrr) & $\ldots$ & 2.0 & $\mathrm{DE}$ & Ha7981 (xxrr) & $\ldots$ & 3.5 & $\mathrm{CD}$ \\
\hline XxRR & OH 8245 & 2.0 & $\mathrm{DE}$ & 8053 (xxR_) & OH7530 & 3.5 & $\mathrm{CD}$ \\
\hline xxR_ & $\mathrm{OH} 7530$ & 2.0 & DE & $\mathrm{xxRr}$ & $\mathrm{OH} 8245$ & 3.0 & CD \\
\hline $\mathrm{xxR} \overline{\mathrm{R}}$ & OH88119 (06.8145) & 1.5 & $\mathrm{E}$ & xxRR & OH88119 (06.8145) & 3.0 & $\mathrm{CD}$ \\
\hline X_R_ & OH7530 & 1.5 & $\mathrm{E}$ & X_R_ & OH7530 & 3.0 & $\mathrm{CD}$ \\
\hline PI $128216(x x R R)$ & & 1.5 & $\mathrm{E}$ & PI 128216 (xxRR) & & 2.5 & $\mathrm{D}$ \\
\hline$P$ value & $\ldots$ & $<0.0001$ & $\ldots$ & $\ldots$ & $\ldots$ & $<0.0001$ & $\ldots$ \\
\hline $\operatorname{LSD}_{(0.05)}$ & $\ldots$ & 1.1 & $\ldots$ & $\ldots$ & $\ldots$ & 2.2 & $\ldots$ \\
\hline
\end{tabular}

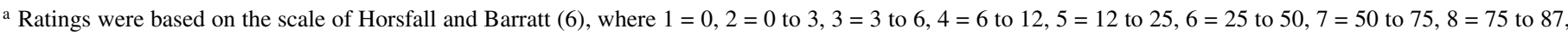
$9=87$ to $94,10=94$ to $97,11=97$ to 100 , and $12=100 \%$ diseased tissue. Plants were rated when $80 \%$ of fruit were mature green (early) or when $80 \%$ of the fruit were ripe (late).

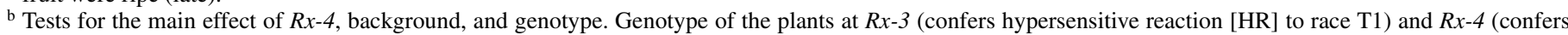
HR to race T3). The alleles at $R x-3$ are represented by X (confers HR) or $\mathrm{x}$ (no HR) and the alleles at $R x-4$ are represented by $\mathrm{R}$ (confers HR) or $\mathrm{r}$ (no HR). Genotypes were inferred from the linked marker loci Rx3-L1 for $R x-3$ and SL10737i and SL10615i for $R x-4$. LSD $=$ least significant difference.

${ }^{c}$ Genetic background based on the crosses of $06.8145 \times \mathrm{OH} 8245,06.8145 \times \mathrm{OH} 7530,06.8145 \times \mathrm{OH} 88119$, and $06.8068 \times \mathrm{OH} 88119$

${ }^{\mathrm{d}}$ Mean disease rating.

e Entries with the same grouping letter are not significantly different based on the $\operatorname{LSD}_{(0.05)}$. 
Three populations were developed from specific IBC lines to test the effect of the chromosome 6 and chromosome 11 locations on HR in the greenhouse. Of 205 plants in the $06.8145 \times$ OH88119 population, 197 gave clear results. In both the 06.8040 $\times$ OH88119 and $06.8068 \times \mathrm{OH} 88119$ populations, 47 of the 48 plants tested were scored unambiguously. The HR response segregated in all three populations and did not significantly deviate from a $3: 1$ ratio in the 06.8040 and 06.8145 populations. A deviation from 3:1 ratio was suggested for the 06.8068 population $(P=0.005)$, with more susceptible progeny than expected. For this population, chromosome 11 marker distortion from the expected 3:1 ratio was also observed in the direction of the susceptible allele $(P=0.04)$. In the two small populations, we could not rule out alternative 13:3 ratios (06.8040 population, $P=$ 0.118 ) or $9: 7$ ratios (06.8068 population, $P=0.869$ ).

Nonparametric marker-trait analysis of the two populations segregating for PI 128216 alleles on chromosome 6 failed to confirm an association between the markers and the HR response (Table 1). All segregating markers on chromosome 11 were highly associated with HR $(P<0.0002)$ in all three confirming populations. Taken together, these results do not support a genetic effect from chromosome 6 but strongly implicate a locus on chromosome 11. The locus on chromosome 11, which we refer to as $R x-4$, was sufficient to elicit an HR when challenged with the race T3 strain $X c v 761$.

In order to better characterize the location of $R x-4$, we created a linkage map with additional markers on chromosome 11 (Fig. 1). The locus was mapped 20 centimorgans (cM) from SL10737i and $12 \mathrm{cM}$ from SL10615i, the two markers initially associated with HR in the IBC population. Four markers (SSR637, SL10915, TOM144, and TOM196) mapped further away from $R x-4$. CosOH57 mapped $7 \mathrm{cM}$ away from the locus while $3 \mathrm{cM}$ separated SL20181 and $R x-4$. CosOH57 and SL20181 were tested for their association with $\mathrm{HR}$ in the IBC population and the three $\mathrm{BC}_{3} \mathrm{~F}_{2}$ populations as well. As expected, these two markers were highly associated with $\mathrm{HR}$ in all populations where they segregated $(P<0.0001)$ (Table 1$)$. The location of the markers linked to $R x-4$ places the locus near the middle of the short arm of chromosome 11 (Fig. 1).

To determine whether $R x-4$ also provides resistance in the field, four $\mathrm{BC}_{3} \mathrm{~F}_{2}$ populations were grouped by genotype and evaluated for resistance to race $\mathrm{T} 3$. The severity of disease increased between early and late rating periods (Table 2). The susceptible control, OH88119, was the most susceptible while the resistant controls, PI 128216 and Ha7981, were among the most resistant in both ratings. The main effect of marker genotype was highly significant in both the early $(P=0.003)$ and late $(P=0.0001)$ ratings. The most resistant plots were either homozygous or heterozygous for the PI 128216 allele on chromosome 11, while the most susceptible were homozygous for the allele derived from $\mathrm{OH} 88119$, OH8245, or OH7530. In the early rating, plots homozygous for the PI 128216 allele had a mean rating of 1.9 and were more resistant than heterozygotes with a mean rating of 2.5 or homozygotes for the susceptible allele with a mean rating of 4.1. In the late rating, however, PI 128216 homozygotes and heterozygotes were not significantly different, with mean ratings of 3.6 and 4.3 , respectively. Both were significantly more resistant than homozygotes with the $\mathrm{OH}$ allele, with a mean rating of 7.9. The effect of $R x$-3 was not significant in the $06.8145 \times 0 \mathrm{OH} 7530 \mathrm{~F}_{2}$ population in either rating $(P>0.78)$, nor was the interaction between $R x$-3 and the PI 128216 locus on chromosome $11(P>$ $0.70)$. These results confirm the race-specificity of these two loci.

The main effect of genetic background was also statistically significant in the early rating $(P=0.046)$. Regardless of marker class on chromosome 11, plots derived from crosses to OH8245 had a mean rating of 2.3 and were more resistant than the plots derived from crosses to $\mathrm{OH} 88119$, with a mean rating of 3.2. Plots derived from crosses to $\mathrm{OH} 7530$ had a mean rating of 2.5 and were not significantly different from the others. This effect was marginally nonsignificant $(P=0.108)$ in the late rating, with the mean ratings of the OH8245, OH7530, and OH88119 backgrounds as 4.7, 4.7, and 5.8, respectively (Table 2).

\section{DISCUSSION}

We identified molecular markers from PI 128216 that were associated with the HR response to bacterial spot race T3. Nonparametric single-marker analysis in an IBC population implicated two genomic locations. Subsequent testing of independent populations, however, confirmed the association of chromosome 11 with HR and did not support an effect from chromosome 6. Gametic phase disequilibrium between chromosome 6 and 11 in the IBC population provides an explanation for the spurious detection of association. These results illustrate the importance of confirming generations when mapping traits of interest.

In the two smallest confirming populations, $06.8068 \times$ OH88119 and $06.8040 \times \mathrm{OH} 88119$, segregation ratios other than $3: 1$ could not be ruled out and $06.8068 \times \mathrm{OH} 88119$ did not fit a 3:1 ratio. Population size limited our ability to interpret gene numbers in these populations. A shift of only three individuals from the susceptible to the HR class would create a nonsignificant $\chi^{2}$ value relative to a $3: 1$ ratio. The 48 individuals screened from these populations were not sufficient to distinguish between a $3: 1$ and alternative segregation ratios. In addition, markers on chromosome 11 detected segregation distortion in the 06.8068 population in the direction of susceptible alleles. In contrast, when 200 individuals were screened from the $06.8145 \times$ OH88119 population, the only ratio from which the population did not greatly deviate was $3: 1$, providing strong evidence for a single dominant gene. The locus on chromosome 11 alone was sufficient to confer the HR response, and no supporting data for a locus on chromosome 6 was evident. The importance of the locus on chromosome 11 was confirmed by the field results where the PI 128216 allele increased resistance to spot race T3. Taken together, these results indicate that a single, dominant gene on chromosome 11 from PI 128216 is sufficient to confer HR to bacterial spot race T3.

The nomenclature of Xanthomonas resistance loci in tomato is inconsistent in the literature. Current resistance loci include $R x-1$, $R x-2$, and $R x-3$ which denote QTL from Ha7998 conferring HR resistance to race $\mathrm{T} 1$ (37). This designation was maintained in subsequent studies with regards to $R x$-3, which was shown to confer resistance to race $\mathrm{T} 1$ in the field (36). A source of unmapped resistance to race T3 from Ha7981 has been named $X v 3$, where "Xv" refers to the species (X. vesicatoria) and the " 3 " refers to the race $(15,24)$. This designation illustrates the problem with using taxonomic designations in the name because Xanthomonas taxonomy has been revised several times and T3 strains tend to be $X$. perforans, not $X$. vesicatoria. A source of HR to race T4 identified from LA716 has been named $X v 4$ (1). This locus name is also problematic for the reasons discussed above. In consultation with the tomato-breeding community, we propose that the locus identified in this study be denoted as $R x-4$, which indicates resistance to Xanthomonas, locus number 4 . This naming convention is not ideal because it does not provide information regarding the race or the species of bacteria. However, given that the taxonomy is in flux, we believe this name offers the best compromise.

Because $R x-4$ conditions HR in the greenhouse, we designed an experiment to specifically test the effect of this locus under openfield conditions. This was accomplished by grouping individuals based on their genotype at markers linked to the locus. Our results indicate that $R x-4$ also contributes to resistance in the field. In previous reports, HR was not highly correlated with resistance in the field (22). There are likely several factors, genetic and environmental, involved in field resistance. Our results from the early rating suggest, for example, that genetic background may 
affect the level of resistance. Furthermore, data from the disease evaluation suggest that $R x-4$ does not exhibit complete dominance for resistance in the field. It would be beneficial, therefore, to combine $R x-4$ with other sources of resistance to Xanthomonas spp. as well as with resistance to other bacterial pathogens.

The combination of $R x-4$ with other sources of Xanthomonas resistance will require additional research in some cases. In this study, both PI 128216 and Ha7981 provide some resistance to spot race T3 in the field. Resistance to race T3 from Ha7981 has not yet been genetically characterized (7). Further characterization of the Ha7981 source is needed to determine how resistance can best be combined. Yang et al. (35) identified a QTL with large effect from PI 114490 that contributes to resistance to spot races $\mathrm{T} 1, \mathrm{~T} 2, \mathrm{~T} 3$, and $\mathrm{T} 4$ that was associated with the markers TOM144, TOM196, and SSR637 on chromosome 11. Although these markers are in the same general chromosomal region as $R x$ 4 , the relationship between these loci is unknown. These two sources are most likely not allelic because resistance from PI 128216 is race-specific (T3) whereas resistance from PI 114490 is not race-specific and does not confer HR. Further analysis is required to determine the extent of genetic similarity between the two loci.

The markers identified in this study will be useful for markerassisted selection for resistance to spot race T3. We demonstrated that families with PI 128216 alleles at SL10737i and SL10615i were more resistant in the field than families with susceptible alleles. This result suggests that gain can be made for resistance by indirect selection of marker loci. The use of CosOH57 or SL20181 is expected to be more efficient because they are more closely linked to $R x-4$ than SL10737i and SL10615i.

Use of an IBC population to screen for traits from unimproved germplasm is beneficial because, once identified, the trait is in a genetic background that is more easily used in traditional breeding programs. Lines from our $\mathrm{BC}_{2} \mathrm{~S}_{5}$ population are expected to possess only $12.5 \%$ of their genome from the wild donor. The structure of the population also allows for replication, thus allowing more confidence in assessment of traits. We crossed resistant IBC plants with elite material for confirmation of marker-trait associations and to introduce the resistance into more diverse genetic backgrounds. This approach is sometimes referred to as simultaneous discovery and introgression. We have combined $R x$ 4 with $R x-3$ and Pto. The tomato lines and markers reported here should be of use to develop resistant cultivars and to further investigate the basis of resistance.

\section{ACKNOWLEDGMENTS}

We thank T. Aldrich for help with greenhouse and field plantings; T. Joobeur and J. Whittier of the OARDC Molecular and Cellular Imaging Center for support of the Luminex genotyping; the National Research Initiative (NRI) Plant Genome Program of the USDA's Cooperative State Research, Education and Extension Service for a Post-doctoral grant 2007-35300-18316 to M. Robbins; and the USDA/NRI for Plant Genome grant 2004-35300-14651 and Ohio Plant Biotechnology Consortium for Competitive Grant 2007-025 to D. Francis.

\section{LITERATURE CITED}

1. Astua-Monge, G., Minsavage, G. V., Stall, R. E., Vallejos, C. E., Davis, M. J., and Jones, J. B. 2000. Xv4-vrxv4: A new gene-for-gene interaction identified between Xanthomonas campestris pv. vesicatoria race T3 and the wild tomato relative Lycopersicon pennellii. Mol. Plant-Microbe Interact. 13:1346-1355.

2. Berry, S. Z., Aldrich, T. S., Wiese, K. L., and Bash, W. D. 1995. 'Ohio OX38' hybrid processing tomato. HortScience 30:159.

3. Berry, S. Z., Gould, W. A., and Wiese, K. L. 1991. 'Ohio 8245' processing tomato. HortScience 26:1093.

4. Darrigues, A. 2007. Dissecting variation in tomato fruit color quality through digital phenotyping and genetic mapping. Ph.D. dissertation, The Ohio State University, Wooster.

5. Doidge, E. M. 1921. A tomato canker. Ann. Appl. Biol. 7:407-430.
6. Horsfall, J. G., and Barratt, R. W. 1945. An improved grading system for measuring plant diseases. (Abstr.) Phytopathology 35:655.

7. Hutton, S. F. 2008. Inheritance and mapping of resistance to bacterial spot race $\mathrm{T} 4$ (Xanthomonas perforans) in tomato, and its relationship to race T3 hypersensitivity, and inheritance of race T3 hypersensitivity from PI 126932. Ph.D. dissertation, University of Florida.

8. Jones, J. B., Bouzar, H., Stall, R. E., Almira, E. C., Roberts, P. D., Bowen, B. W., Sudberry, J., Strickler, P. M., and Chun, J. 2000. Systematic analysis of xanthomonads (Xanthomonas spp.) associated with pepper and tomato lesions. Int. J. Syst. Evol. Microbiol. 50:1211-1219.

9. Jones, J. B., Lacy, G. H., Bouzar, H., Minsavage, G. V., Stall, R. E., and Schaad, N. W. 2005. Bacterial spot-world wide distribution, importance and review. Acta Hortic. 695:27-34.

10. Jones, J. B., Lacy, G. H., Bouzar, H., Stall, R. E., and Schaad, N. W. 2004. Reclassification of the xanthomonads associated with bacterial spot disease of tomato and pepper. Syst. Appl. Microbiol. 27:755-762.

11. Jones, J. B., and Scott, J. W. 1986. Hypersensitive response in tomato to Xanthomonas campestris pv. vesicatoria. Plant Dis. 70:337-339.

12. Kabelka, E., Franchino, B., and Francis, D. M. 2002. Two loci from Lycopersicon hirsutum LA407 confer resistance to strains of Clavibacter michiganensis subsp. michiganensis. Phytopathology 92:504-510.

13. Lee, S. H., Walker, D. R., Cregan, P. B., and Boerma, H. R. 2004. Comparison of four flow cytometric SNP detection assays and their use in plant improvement. Theor. Appl. Genet. 110:167-174.

14. Lelliot, R. A., and Stead, D. E. 1987. Methods for the Diagnosis of Bacterial Diseases of Plants. Blackwell Scientific Publication Ltd., Oxford.

15. Minsavage, G. V., Jones, J. B., and Stall, R. E. 1996. Cloning and sequencing of an avirulence gene (avrRxv3) isolated from Xanthomonas campestris pv. vesicatoria tomato race 3. (Abstr.) Phytopathology 86:S15.

16. Sahin, F. 1997. Detection, identification and characterization of strains of Xanthomonas campestris pv. vesicatoria by traditional and molecular methods, and resistance in Capsicum species to Xanthomonas campestris pv. vesicatoria pepper race 6. Ph.D. dissertation, The Ohio State University, Wooster.

17. Sahin, F., and Miller, S. A. 1996. Characterization of Ohio strains of Xanthomonas campestris pv. vesicatoria, causal agent of bacterial spot of pepper. Plant Dis. 80:773-778.

18. Scott, J. W. 1997. Tomato improvement for bacterial disease resistance for the tropics: A contemporary basis and future prospects. Pages 117-123 in: Proc. First Int. Conf. Processing Tomato/First Int. Symp. Trop. Tomato Dis. Recife, Brazil. ASHS Press, Alexandria, VA.

19. Scott, J. W., Francis, D. M., Miller, S. A., Somodi, G. C., and Jones, J. B. 2003. Tomato bacterial spot resistance derived from PI 114490; inheritance of resistance to race T2 and relationship across three pathogen races. J. Am. Soc. Hortic. Sci. 128:698-703.

20. Scott, J. W., and Jones, J. B. 1989. Inheritance of resistance to foliar bacterial spot of tomato incited by Xanthomonas campestris pv. vesicatoria. J. Am. Soc. Hortic. Sci. 114:111-114.

21. Scott, J. W., Jones, J. B., and Somodi, G. C. 2001. Inheritance of resistance in tomato to race T3 of the bacterial spot pathogen. J. Am. Soc. Hortic. Sci. 126:436-441.

22. Scott, J. W., Jones, J. B., Somodi, G. C., and Stall, R. E. 1995. Screening tomato accessions for resistance to Xanthomonas campestris pv. vesicatoria, race T3. HortScience 30:579-581.

23. Scott, J. W., Miller, S. A., Stall, R. E., Jones, J. B., Somodi, G. C., Barbosa, V., Francis, D. L., and Sahin, F. 1997. Resistance to race T2 of the bacterial spot pathogen in tomato. HortScience 32:724-727.

24. Scott, J. W., Stall, R. E., Jones, J. B., and Somodi, G. C. 1996. A single gene controls the hypersensitive response of Ha 7981 to race 3 (T3) of the bacterial spot pathogen. Rep. Tomato Genet. Coop. 46:23.

25. Stall, R. E. 1995. Xanthomonas campestris pv. vesicatoria, Pages 167-181 in: Pathogenesis and Host Specificity in Plant Diseases: Histopathological, Biochemical, Genetic and Molecular Bases. U. S. Singh, R. P. Singh, and K. Kphmoto, eds. Elsevier Science, New York.

26. Šutic, D. 1957. Bakterioze crvenog patlidzana (tomato bacteriosis). Posebna Izd. Inst. Zasht. Bilja Beograd (Spec. Ed. Inst. Plant Prot. Beograd) 6:1-65. English summary: Rev. Appl. Mycol. 36:734-735.

27. van Berloo, R. 2008. GGT 2.0: versatile software for visualization and analysis of genetic data. J. Hered. 99:232-236.

28. Van Deynze, A., Stoffel, K., Buell, C. R., Kozik, A., Liu, J., van der Knaap, E., and Francis, D. 2007. Diversity in conserved genes in tomato. BMC Genomics 8:465.

29. Van Ooijen, J. W., and Voorrips, R. E. 2001. JoinMap 3.0, Software for the Calculation of Genetic Linkage Maps. Plant Research International, Wageningen, The Netherlands.

30. Vauterin, L., Hoste, B., Kersters, K., and Swings, J. 1995. Reclassification of Xanthomonas. Int. J. Syst. Bacteriol. 45:472-489.

31. Wang, J. F., Jones, J. B., Scott, J. W., and Stall, R. E. 1994. Several genes in Lycopersicon esculentum control hypersensitivity to Xanthomonas campestris pv. vesicatoria. Phytopathology 84:702-706. 
32. Wehrhahn, C., and Allard, R. W. 1965. The detection and measurement of the effects of individual genes involved in the inheritance of a quantitative character in wheat. Genetics 51:109-119.

33. Yang, W., Bai, X. D., Kabelka, E., Eaton, C., Kamoun, S., van der Knaap, E., and Francis, D. 2004. Discovery of single nucleotide polymorphisms in Lycopersicon esculentum by computer aided analysis of expressed sequence tags. Mol. Breed. 14:21-34.

34. Yang, W., and Francis, D. M. 2005. Marker-assisted selection for combining resistance to bacterial spot and bacterial speck in tomato. J. Am. Soc. Hortic. Sci. 130:716-721.

35. Yang, W., Miller, S. A., Scott, J. W., Jones, J. B., and Francis, D. M. 2005.
Mining tomato genome sequence databases for molecular markers: Application to bacterial resistance and marker assisted selection. Acta Hortic. 695:241-250.

36. Yang, W., Sacks, E. J., Ivey, M. L. L., Miller, S. A., and Francis, D. M. 2005. Resistance in Lycopersicon esculentum intraspeciflc crosses to race T1 strains of Xanthomonas campestris pv. vesicatoria causing bacterial spot of tomato. Phytopathology 95:519-527.

37. Yu, Z. H., Wang, J. F., Stall, R. E., and Vallejos, C. E. 1995. Genomic localization of tomato genes that control a hypersensitive reaction to Xanthomonas campestris pv. vesicatoria (Doidge) Dye. Genetics 141: 675-682. 